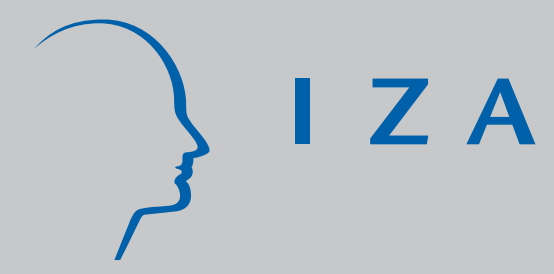

IZA DP No. 1392

Is the Household Demand for In-Home Services Sensitive to Tax Reductions? The French Case

Anne Flipo

Denis Fougère

Lucile Olier

November 2004 


\title{
Is the Household Demand for In-Home Services Sensitive to Tax Reductions? The French Case
}

\author{
Anne Flipo \\ INSEE, Paris \\ Denis Fougère \\ CNRS, CREST-INSEE, \\ CEPR and IZA Bonn \\ Lucile Olier \\ INSEE, Paris
}

\section{Discussion Paper No. 1392 \\ November 2004}

\author{
IZA \\ P.O. Box 7240 \\ 53072 Bonn \\ Germany \\ Phone: +49-228-3894-0 \\ Fax: +49-228-3894-180 \\ Email: iza@iza.org
}

\begin{abstract}
Any opinions expressed here are those of the author(s) and not those of the institute. Research disseminated by IZA may include views on policy, but the institute itself takes no institutional policy positions.
\end{abstract}

The Institute for the Study of Labor (IZA) in Bonn is a local and virtual international research center and a place of communication between science, politics and business. IZA is an independent nonprofit company supported by Deutsche Post World Net. The center is associated with the University of Bonn and offers a stimulating research environment through its research networks, research support, and visitors and doctoral programs. IZA engages in (i) original and internationally competitive research in all fields of labor economics, (ii) development of policy concepts, and (iii) dissemination of research results and concepts to the interested public.

IZA Discussion Papers often represent preliminary work and are circulated to encourage discussion. Citation of such a paper should account for its provisional character. A revised version may be available directly from the author. 
IZA Discussion Paper No. 1392

November 2004

\section{ABSTRACT \\ Is the Household Demand for In-Home Services Sensitive to Tax Reductions? The French Case}

Our paper examines the impact of tax reductions on the demand for services in the home. For that purpose, we estimate a structural model of demand for such services by using household individual data collected by INSEE (Paris) in 1996. In this model, the net hourly wage paid to the domestic employee, the household preferences for consumption of in-home services and the decision to take advantage of the tax reduction are considered as endogenous variables. Estimation of the econometric model uses the fact that some households are observed to consume domestic services and to take advantage of the tax reduction, while others either consume such services but do not take advantage of the tax reduction, or do not consume these services at all. Its identification relies on an exclusion restriction resulting from the tax credit schedule. Results show that the probability of consuming in-home services increases with age and income. A ten per cent increase in the tax reduction would increase from 45.9 to 50.8 per cent the proportion of households benefiting from the tax reduction among those who consume paid in-home services. Moreover, 13.5 per cent of households who do not actually consume such services would do so after the ten per cent increase in the tax reduction. These simulated variations would mainly concern high-income households.

JEL Classification: $\quad$ D13, J12

Keywords: $\quad$ services in the home, tax reduction, household demand, labor cost

Corresponding author:

Denis Fougère

CREST-INSEE,

15 Boulevard Gabriel Peri

92245 Malakoff Cedex

France

Email: fougere@ensae.fr 


\section{Introduction}

Since the early 1990s, the French authorities have introduced various measures aimed at encouraging the expansion of employment in the home by reducing its cost (tax reductions, exemption from social insurance contributions, specific benefits) and by easing the formalities connected with hiring. The jobs covered by legislation voted from 1991 on are service activities carried out in the employer's home: housework and other services, child care, educational support, care for an elderly or handicapped person. Three main measures may be distinguished.

1. Since 1991, households employing paid and reported help are granted an indirect subsidy in the form of a tax reduction for "home employment". They are allowed to deduct from their income tax $50 \%$ of the sums paid out, subject to an annual ceiling. This ceiling was set at 25,000 French Francs (FF) in 1992, subsequently raised to 26,000 FF in 1994 and later to 90,000 FF in 1995. In 1997 it was brought down to 45,000 FF.

2. When the household makes use of a home help for the purpose of looking after a child aged less than six in the home, it also receives an allowance called AGED, ${ }^{1}$ corresponding to the exemption of the payment of all or part of the employees' and employers' social security contributions.

3. Since 1991, the employing household has had a choice of two methods for calculating employees' and employers' contributions: either on a flat-rate basis, or an actual basis. In the former case, the contributions are calculated on a flat-rate base equal to the hourly minimum wage multiplied by the number of hours worked. In the latter case, the calculation of contributions is based on the actual wage. The flat-rate calculation is less costly for the employer, but the cash benefits (retirement pension, unemployment or sickness benefit, etc.) received by the employee are lower than when the calculation is made on the remuneration actually received.

Moreover, the five-year law dated December 1993 instituted the "chèqueemploi-service". ${ }^{2}$ The aim was to facilitate person-to-person relations by easing

\footnotetext{
${ }^{1}$ AGED is the French acronym for "Allocation pour la Garde d'Enfant à Domicile" (namely, allowance for child care in the home).

${ }^{2}$ The so-called "chèque-emploi-service" is a voucher obtainable from e.g. banks and post offices usable on certain conditions to pay for domestic service bypassing the normal administrative procedures.
} 
for both parties the complex administrative formalities associated with the reporting of the employment. It enables the employer to leave the task of calculating the amount of the social security contributions. In addition, Parliament has tried to improve and expand the supply of services obtained through the network of nonprofit associations: the specific notion of authorised organisations for services to individuals was introduced on this occasion. This status is granted to non-profit associations whose activities include child care in the parents' home or assistance to the elderly and the handicapped. Lastly, laws have been passed introducing a statutory obligation for the financing of vocational training of employees at a rate of $0.15 \%$, paid by the employer.

The net result of these arrangements in terms of jobs is nevertheless difficult to establish (see, for instance, Cealis and Zilberman, 1997, and Piketty, 1998). French Labor Force Surveys collected by INSEE (Institut National de la Statistique et des Etudes Economiques, Paris) make it possible to estimate the number of jobs in the home created since the introduction of the support arrangements in 1991. Numbers grew strongly between 1991 and 1997, when it was calculated that there were 470,000 people employed in the home, meaning an increase of around $120,000(+33 \%)$ since 1991, in a period when total employment remained virtually unchanged $(-0.4 \%)$ and employment in services grew very slightly $(+2 \%)$.

One important question, raised simultaneously in different European countries (see, for instance, European Commission, 1994, Antonnen and Spiliä, 1996, Preston, Labeaga and Sanchis, 1997), is whether the surge in the number of wageearners in the sector of in-home services since the introduction of the arrangements in support of home employment reveals the creation of new jobs that would not have existed in the absence of such measures, or whether some of these jobs have previously existed in the "black market" but the law has made them regular. ${ }^{3}$

\footnotetext{
${ }^{3}$ On this point, we should remark that the debate in Europe has focused on the effect of public policies (including tax reductions) on the creation of new jobs in the sector of in-home services, while the U.S. literature has mainly examined the effects of child care tax credits on female labor supply (see, for instance, recent contributions by Averett, Peters and Waldman, 1997, Kimmel, 1998, Blau and Hagy, 1998). Obviously, we should also examine the effect of the tax reduction policy on female labor supply. Due to the complexity resulting from the introduction of at least two supplementary endogenous variables (namely, the female labor market wage, and the number of hours worked by active women), we have assumed here that female labor supply is an exogenous decision. Let us recall that, in France, over the period 1991-1997, the female labor force participation rate (for women older than 15) grew slightly from 46.0 to $47.2 \%$, while unemployment rate has sharply increased, going from 9 to $12.3 \%$. These changes explain why we prefer to focus on the effect of the tax reduction on the household decision to hire domestic employees, rather than on its effect on female labour supply.
} 
In other words, do the reduction in overall labor cost (including employees' and employers' social security contributions) of jobs in the sector of services to individuals, as a result of official subsidies and tax exemptions, stimulate the demand for the services by attracting new consumers, whose demand had not previously been effective? While the influence of income and of certain sociological factors on the decision to consume in-home services is clearly identified, that of the price is more difficult to analyse. And yet it is precisely on this point that the question arises as to the effectiveness of public arrangements aimed at reducing the cost of those services. If the use of family help is merely a question of tastes, there must be doubts concerning the necessity of these arrangements. On the other hand, if it turns out that such employment is price-sensitive, a policy of reducing the cost of the services will be effective.

The potential for expansion seems considerable, in fact. Households are expressing substantial unsatisfied needs. In 1996, more than 4 million households expressed the need for help in their daily lives (Flipo, 1996). Of these, more than half would have liked to have help with everyday domestic chores (housework, shopping, laundry, etc), $19 \%$ for services connected with improving their household environment (gardening, for example), and $9 \%$ for child care. The financial constraint probably explains part of the failure to consume such services: $66 \%$ of households declared having no budget available for the purpose. But prejudice can also hold back consumption of in-home services, with $18 \%$ of households regarding it as a luxury, $18 \%$ having difficulty in finding someone suitable, $12 \%$ saying they would be embarrassed to employ someone else. The transformation of these needs into actual employment therefore requires both a process of making demand effective and greater professionalism among the potential employees.

In France, the "family-jobs" sector is defined today in terms of two quite distinct professional branches: home-help services and services in the home (the so-called "domestic services"). Home helps are professionals in the social sector. They perform a public service either directly (local authorities) or through delegation (associations under contract). These employees are covered by one of the three collective agreements in force ("aide à domicile en milieu rural", "travailleuses familiales", "organismes d'aide à domicile"), ${ }^{4}$ or by the rules governing the local authority civil service. Wage-earners in the private sector of services in the home are, for their part, employed by private individuals on a personal basis or within the framework of services provided by an authorised organisation. Since

\footnotetext{
${ }^{4}$ This means home help in rural areas, female family workers, and home-help organisations, respectively.
} 
1980 they have been covered by the collective agreement for household employees. In parallel with the evolution of the legislation regarding family employment, the labor market has become considerably more complex, and more people and bodies have become involved: agency associations, intermediary associations, authorised associations for services to individuals, self-employed individuals. The complexity of the field covered by family employment, both on the demand side (characterized by highly heterogeneous requirements) and on the supply side (marked by the widely diverse status of the individuals and contractual relationships involved) makes overall diagnosis difficult.

In our paper, examination of the influence of price on the use of in-home services will therefore relate only to domestic services consisting of help in everyday life: general housework, everyday cleaning and ironing, whether provided by a domestic servant or the employee of a commercial cleaning firm. This service can be carried out alongside child caring in the home. The data set we use has been collected by INSEE (Institut National de la Statistique et des Etudes Economiques, Paris) in 1996. Because the law introducing a tax reduction for households consuming paid services in the home was passed in 1991, and because the questionnaire of the survey does not include retrospective questions, we cannot use the change in the law as a natural experiment. Consequently our strategy is to estimate a structural static econometric model whose estimation uses the fact that some households are observed to consume domestic services and to take advantage of the tax reduction, while others either consume such services but do not take advantage of the tax reduction (in particular, because their employee does not want to be declared to the tax administration), or do not consume these services at all.

Our model comprises three simultaneous equations, the first equation specifying the net market price of in-home services, the second characterizing the household preferences, and the third representing the decision to take advantage of the tax reduction by declaring the domestic employee to the tax administration. The household decision to consume in-home services is deduced from the structural equation that compares the net market price for these services and the household reservation price. To derive this equation, we assume that the household utility function has a Box-Cox form. Identification of the parameters of the consumption decision equation relies crucially on an exclusion restriction resulting from the tax schedule; namely, the presence of a kid less than six years old in the household affects (by law) the net hourly price actually paid, but this agediscontinuity dummy variable is assumed not to influence directly the household 
preference for consumption of in-home services and the household decision to take advantage of the tax reduction. The willingness to benefit from the tax reduction is supposed to increase with the value of the difference between the hourly market prices for the services before and after tax reduction. Our model treats explicitly the potential endogeneity of the joint decision to consume domestic services and to take advantage of the tax reduction by assuming that random terms affecting the three equations of the model are potentially correlated. The model is estimated using a rather homogeneous subsample, single people and couples at least one of whom needs permanent care being excluded from our study. ${ }^{5}$

We insist on the fact that our structural estimation concerns only the dichotomous decision to consume in-home services (the "extensive margin"); it ignores the "intensive margin", namely the quantity of in-home services (i.e. the number of hours) that is consumed by the household. In fact, our theoretical model yields the optimal number of hours that the household is ready to consume (see equation 8 in section 2). But, because of the limited size of our sample, we do not try to estimate a more general model in which a fourth equation is added to take into account the endogeneity of the quantity of in-home services that the household actually consumes. In other terms, to avoid additional difficulties resulting from the endogeneity of this variable, we choose to exclude it from our econometric model. Consequently, it is impossible to use this model to predict the effect of a change in the net market price on the quantity of consumed hours, and thus to estimate a structural price elasticity.

Section 2 presents the simple static theoretical model from which the econometric model is derived. In this model we assume that the household is willing to pay for services in the home if and only if the market price of these services is lower than the household reservation price. Section 3 describes the data. Section 4 presents the econometric model. The estimation results are commented in Section 5, which also includes simulations of prices that would have been paid by households who do not consume in-home services, and simulations of the effects of a ten per cent increase in the tax reduction. Section 6 concludes.

\footnotetext{
${ }^{5}$ We will not analyse nursing home care, supplied whether through public social help for families or by the private sector. For persons requiring permanent care, in-home paid services are tantamount to an imposed alternative to residence in a hospital or a retirement home, the quantity being determined as a function of assessed needs based on a scale of dependence and with the price set according to a means test carried out by the authorities. As a result, the problems involved in consumption of such services and those relating to the influence of the financial constraint are stated in quite different ways (see, for instance, the studies by Nyman and Bricker, 1989, and by Gertler and Waldman, 1992).
} 


\section{The theoretical model}

Our model is a static model in which we assume that the household is willing to pay for services in the home if and only if the market price of these services is lower than the household reservation price. In such a context, it is clear that the public authorities should be interested in knowing the distribution of the household willingness to pay. This knowledge should allow them to predict the impact of public subsidies on the demand for this type of services.

So let us consider an economy without savings in which $a$ represents the household demand (measured in hours) for services in the home. The unit price of these services is equal to $P_{a}$, and $C$ represents the household consumption for other goods, whose price is equal to $P_{c}$. The household maximizes a utility function denoted $U(C, a)$; its budget constraint is

$$
P_{c} C+P_{a} a \leq R
$$

where $R$ is the household disposable income. Let us denote $p_{a}=P_{a} / P_{c}$ the (constant) relative price of the services in the home. The budget constraint becomes

$$
C+p_{a} a \leq W
$$

with $W=R / P_{c}$. Then $W$ corresponds to the household income expressed in terms of the price of the other goods. Because $a$ is generally low relatively to $C$, $R$ is very close to $P_{c} C$. Thus it is possible to normalize the price of $C$ and to set it equal to 1 . The program that the household has to solve is then

$$
\max _{C, a} U(C, a)
$$

subject to

$$
C+p_{a} a \leq R
$$

The marginal rate of substitution, which is defined as

$$
r(C, a)=U_{a}^{\prime}(C, a) / U_{c}^{\prime}(C, a)
$$

may be viewed as the reservation price for services in the home. In other terms, this is the price that the household is ready to pay for an additional hour of services. In equation (1), the first-order derivative of $U$ with respect to $x$, denoted $U_{x}^{\prime}$, is the marginal utility of $x$. The household is willing to consume services in the home if its reservation price for these services, which is evaluated at the level 
$a=0$ (namely when the household does not consume any service in the home, or when $C=R$ ), is higher or equal to their market price, i.e.

$$
a>0 \Leftrightarrow r(R, 0) \geq p_{a}
$$

If $a>0$, then $a$ is determined by the following condition, which is derived from the budget constraint:

$$
r(C, a)=p_{a}
$$

Now let us assume that the utility function is separable and has the Box-Cox following form

$$
U(C, a)=B \frac{(\lambda+a)^{\alpha}}{\alpha}+\frac{C^{\beta}}{\beta} \quad \text { with } \alpha<1 \text { and } \beta<1 .
$$

In this expression, $U$ is defined up to some monotonically increasing function $B$ which characterizes the household preferences. This utility function is strictly concave with respect to $C$ and $a$. This function is preferred to a CES utility function, because it does not constraint the elasticity of substitution with respect to the relative price $p_{a}$ to be constant. In particular it may depend on the level of the consumption for services in the home and on the household income. Anyway let us recall that the CES utility function may be obtained as a special case of the function (4) by setting $\alpha=\beta$ and by using the increasing function $F(x)=x^{1 / \alpha}$. If the utility function is specified by equation (4), the reservation price is defined by

$$
r(C, a)=B(\lambda+a)^{\alpha-1} C^{1-\beta}
$$

or equivalently by

$$
\ln r(C, a)=\ln B+(\alpha-1) \ln (\lambda+a)+(1-\beta) \ln C
$$

According to condition (2) and to equation (6), the household consumes a positive quantity of services in the home if and only if

$$
\ln B+(\alpha-1) \ln \lambda+(1-\beta) \ln R \geq \ln p_{a}
$$

Thus the demand for services in the home is

$$
a=\left\{\begin{array}{l}
a^{*} \text { if condition (7) is verified, } \\
0 \text { otherwise, }
\end{array}\right.
$$

where $a^{*}>0$ is the solution of the equation

$$
\ln B+(\alpha-1) \ln \left(\lambda+a^{*}\right)+(1-\beta) \ln \left(R-p_{a} a^{*}\right)-\ln p_{a}=0
$$




\section{The data}

This model has been estimated using data coming from the "Neighbourhood Services" Survey (Enquête sur les Services de Proximité) conducted by INSEE (Institut National de la Statistique et des Etudes Economiques, Paris) in June 1996. In this survey households provide information on the domestic help they received regularly on the date of the survey, the identity of the service-provider (family member, neighbour, friend, domestic employee, firms, family workers, etc.), the type of service provided (housework, ironing, etc.), the monthly net wage $W_{a}$ paid to the service-provider before tax reductions, ${ }^{6}$ and the corresponding number of hours (denoted $a$ ). With this information we calculate the net hourly price paid for the service as $\widetilde{p}_{a}=W_{a} / a$. It is the net hourly wage paid to the household personnel before tax reduction in a person-to-person relationship, whether within the regulatory framework or otherwise; it can also correspond to the price paid to a service company. The household was also asked about receipt of tax reductions induced by the employment of family helpers in the home. On the other hand, no information was obtained as to whether social security contributions were paid on a flat-rate or actual basis. However, when the household is the direct employer, it is the flat-rate basis that is most frequently applied.

For reasons set out earlier, the study covers only the $N=2,913$ couples in which the reference individual (most frequently the man) is aged between 25 and 64. Households including at least one dependent person were excluded from the analysis. ${ }^{7}$ In this subsample 174 households use domestic services. Among these 174 households, 80 (respectively, 94) households take (respectively, do not take) advantage of the tax reduction. There is wide variation in the net hourly wages paid out. The average net hourly wage is 46 francs, but for one quarter of households it is below 37 francs and for another quarter above 50 francs. Even when the first and last deciles of the distribution are excluded, the interdecile ratio is still 2 to 1 (see Table 1 ).

${ }^{6}$ INSEE's survey on "Neighbourhood Services" accordingly identifies paid recourse to a domestic help for everyday chores (housework, ironing, gardening, etc.). In 1996, 1.8 million households spent more than 20 billion French francs on these services, representing the equivalent of 250,000 full-time jobs (this amount does not include the wages paid by households to social workers who care at home about old dependent persons or children less than 11).

${ }^{7}$ See note 5 . 
Table 1

The hourly net wage, in francs, paid by households consuming domestic services

\begin{tabular}{llllllll}
\hline $\begin{array}{l}\text { Hourly net wage } \\
\left(\widetilde{p}_{a}\right)\end{array}$ & Overall & $\begin{array}{l}\text { At least one kid } \\
\text { less than } 6\end{array}$ & $\begin{array}{l}\text { No kids } \\
\text { less than } 6\end{array}$ & $\begin{array}{l}\text { Living in } \\
\text { Paris }\end{array}$ & $\begin{array}{l}\text { Not living } \\
\text { in Paris }\end{array}$ & $\begin{array}{l}\text { With tax } \\
\text { reduction }\end{array}$ & $\begin{array}{l}\text { Without tax } \\
\text { reduction }\end{array}$ \\
\hline Mean & 46.37 & 38.72 & 49.63 & 51.87 & 43.96 & 42.71 & 49.48 \\
Median & 41.86 & 39.00 & 46.51 & 50.00 & 40.00 & 39.09 & 50.00 \\
1st quartile & 37.50 & 31.00 & 39.00 & 47.10 & 36.08 & 36.00 & 40.00 \\
3rd quartile & 50.00 & 50.00 & 50.00 & 53.88 & 46.51 & 47.40 & 52.83 \\
Interdecile ratio & 2.01 & 2.18 & 1.76 & 1.62 & 2.08 & 1.95 & 1.72 \\
\hline Proportion & 100 & 29.89 & 70.11 & 30.46 & 69.54 & 45.98 & 54.02 \\
\hline
\end{tabular}

Subsample: Couples whose head has between 25 and 64 years old and who use domestic help $\left(N_{1}=174\right)$.

Source: "Services de proximité" Survey, INSEE (1996).

The hourly net wage paid to the domestic employee is lower when there is at least one kid less than six years old in the household (see Table 1). The place of residence of the employer plays also an important role: the Parisian market stands out for the higher prices paid (see Table 1). ${ }^{8}$ The price paid out to the serviceprovider is generally lower if the household benefits from the tax reduction. Half the households benefiting from the tax reduction pay a net wage of less than 40 francs, whereas half of those that do not benefit from the reduction pay less than 50 francs an hour (see Table 1). In return for the social security coverage offered to the employee, the employer has perhaps a tendency to negotiate a smaller net wage. Perhaps also, this difference in wage incorporates certain implicitly-induced costs resulting from the constraint to report the wage-earning employment (as regards termination, for example).

The data coming from the "Neighbourhood Services" Survey make it possible to reconstitute:

- the gross price of the service declared, including social security contributions paid out when the service-provider is reported by the employer to the tax administration; in this case, contributions are calculated on a flat-rate basis ${ }^{9}$ and this price is equal to $p_{a}^{g}=\widetilde{p}_{a}+26.05$;

\footnotetext{
${ }^{8}$ It is difficult to interpret the effect of the variable "Paris" on the hourly net wage as a supply-side or a demand-side effect. It may capture the fact that households in Paris are richer and/or that the wage may reflect the higher willingness-to-pay of Parisian households which have to face generally longer working hours, due in particular to longer travel time from and to work (Fermanian and Baessa, 1997). We will go back to this point when presenting the wage equation in the next section.

${ }^{9}$ The model has also been estimated with social contributions calculated on a real basis.
} 
- the price of the service effectively borne by the household, denoted $p_{a}$, which takes into account where appropriate the tax reduction granted to households employing family workers.

For calculating $p_{a}$, we have created two dummy variables denoted $r_{d}$ and $k_{6} ; r_{d}$ takes the value 1 if the household declares that it benefits from this tax reduction, 0 otherwise; $k_{6}$ takes the value 1 if the household receives the allowance for child care in the home, 0 otherwise. ${ }^{10}$ In the absence of information on the taxes paid by the households, it is assumed that those who state that they benefit from the tax reduction do so to the maximum extent (half the gross outlay, i.e. the wages and contributions paid). It turns out in practice that the gross outlay of these households, taking account of the average working time of domestic employees, does not exceed the tax-reduction ceiling. Consequently, we calculate the value of the effective price of the service as follows:

$$
p_{a}= \begin{cases}0.5 \widetilde{p}_{a} \quad & \begin{array}{l}
\text { if the household benefits from the tax reduction } \\
\left(r_{d}=1\right) \text { and if it receives the allowance for }
\end{array} \\
& \text { child care in the home }\left(k_{6}=1\right), \\
0.5 p_{a}^{g} & \begin{array}{l}
\text { if the household benefits from the tax reduction } \\
\left(r_{d}=1\right) \text { and if it does not receive this }
\end{array} \\
& \text { allowance }\left(k_{6}=0\right), \\
\widetilde{p}_{a} \quad & \text { otherwise }\left(r_{d}=0\right) .\end{cases}
$$

Definition (9) can be written more compactly as

$$
\ln p_{a}=\left(\ln \widetilde{p}_{a}\right) \times\left(1-r_{d}+r_{d} k_{6}\right)+(\ln 0.5) \times r_{d}+\ln \left(\widetilde{p}_{a}+26.05\right) \times r_{d}\left(1-k_{6}\right)
$$

Between the .025 and .975 quantiles of the sample distribution of prices $\widetilde{p}_{a}{ }^{11}$ $\ln \left(\widetilde{p}_{a}+26.05\right)$ may be approximated very precisely by the linear relationship $\ln \left(\widetilde{p}_{a}+26.05\right) \approx 1.7351+0.6708 \ln \widetilde{p}_{a}$ obtained by ordinary least squares $\left(R^{2}=\right.$ 0.994). This implies that

$$
\ln p_{a} \approx \ln \widetilde{p}_{a}+(\ln 0.5) \times r_{d}+\left(1.7351-0.3292 \ln \widetilde{p}_{a}\right) \times r_{d}\left(1-k_{6}\right)
$$

Results are essentially the same than the ones which are obtained when calculations are made on a flat-rate basis.

${ }^{10}$ See note 1.

${ }^{11}$ These quantiles are equal to 20 and 120 French Francs, respectively. 


\section{Specification of the econometric model}

Households are assumed to be perfectly rational and informed regarding the measure. A household which declares that it does not benefit from the tax reduction has no interest in paying the social security contributions and it is assumed that it obtains the service "unofficially", namely in the underground labor market where prices are assumed to be different from the prices paid in the "regular" labor market. Many anecdots suggest that the underground labor market for domestic services is wider in big cities, and that "unofficial" labor supply for these domestic services is provided by "regular" workers who are part-time employed, either as employees in cleaning firms or as house-keepers. Many households are reluctant to leave the keys of their house or apartment to workers who have no recommendation, and who are often unskilled immigrants, even if they are "regular" workers. They prefer to pay, often at higher prices, underground workers who have been recommended to them by friends or neighbours. This makes clear that the decision to hire a "regular" versus an "irregular" employee is based not only on their relative wages but also on other aspects, such as private information on their abilities and honesty.

These arguments lead us to make two assumptions. First, for incorporating differences between distributions of wages in the "regular" and "irregular" labor markets, we assume that the net hourly price for services in the home is assumed to be a log-linear function of some covariates $Z_{p}$ and of the indicator $r_{d}$ :

$$
\ln p_{a}=Z_{p} \delta+\left(r_{d} \times Z_{p}\right) \eta+\varepsilon_{1}
$$

where $\delta$ and $\eta$ are vectors of parameters respectively associated with the covariates $Z_{p}$ and the interaction terms $\left(r_{d} \times Z_{p}\right)$, while $\varepsilon_{1}$ is a normally distributed random term. ${ }^{12}$ This assumption, which implies that the dummy variable $r_{d}$ affects only the mean of the price distribution through its interactions with the covariates $Z_{p}$, is coherent with equation (10) if we set $\ln \widetilde{p}_{a}=Z_{p} \delta+\varepsilon$ and if we include the dummy

\footnotetext{
${ }^{12}$ Several arguments (such as adverse selection resulting from the non-observability of individual abilities of applicants to domestic jobs, scarcity of skilled domestic workers, segmentation of local markets, etc.) suggest that the price equation (11) should be seen as a supply-side equation, which means that households with characteristics $Z_{p}$ are essentially price-takers and are faced with a unique price $p_{a}$ depending on their localization (living or not in Paris) and the type of domestic tasks they need (childcare and/or cleaning, etc.). Anyway, due to the lack of relevant information on the personal attributes and preferences of domestic employees, we are not able to distinguish between supply-side and demand-side effects on the price for in-home services, and consequently we cannot estimate a partial equilibrium price equation.
} 
variable $k_{6}$ in the covariate vector $Z_{p}$. Looking at Table 1 , we expect $\left(r_{d} \times Z_{p}\right) \eta$ to be negative. Secondly, to take into account the potential endogeneity of the decision to benefit from the tax reduction, we assume that the observable variable $r_{d}$ is generated by the following probit model:

$$
r_{d}=\mathbf{1}\left(r_{d}^{*}>0\right)=\mathbf{1}\left(Z_{d} \mu-Z_{p} \eta+\varepsilon_{0}>0\right)
$$

where $\mathbf{1}($.$) is the indicator function taking the value 1$ if the expression between parentheses is true (0 otherwise), $r_{d}^{*}=Z_{d} \mu-Z_{p} \eta+\varepsilon_{0}$ is a latent variable that can be interpreted as the willingness to benefit from the tax reduction (or, in other terms, to hire a "regular" rather than an "irregular" worker), $Z_{d}$ is a vector of observed covariates, $\mu$ is a vector of (unknown) parameters, and $\varepsilon_{0}$ is a normally distributed random term with mean 0 and variance equal to 1.For identifiability reasons, the vector $Z_{d}$ must include at least one regressor which does not belong to the vector $Z_{p}$ (see, for instance, Maddala, 1983, Chapter 5.7, p.120). Let us remark that under assumptions $(12)$, the difference $\left(-Z_{p} \eta\right)$ between the hourly net wages in the "irregular" and "regular" labor markets is assumed to shift the intercept of the latent index $r_{d}^{*}$, which implies that, other things being equal, the willingness to benefit from the tax reduction increases with the value of this difference. Specification (12) allows to simulate very easily the effect of a change in the level of the tax reduction on the household decision to benefit from this reduction. For instance, the effect of a ten per cent increase in the level of the tax reduction $^{13}$ will be simulated by adding $\ln 0.9$ to the intercept of the estimate of $Z_{p} \eta$.

Finally we assume that the household preferences $B$ depend on some sociodemographic variables $Z_{b}$ through the log-linear specification

$$
\ln B=Z_{b} \gamma+\varepsilon_{2}
$$

where $Z_{b}$ is a vector of observed covariates, $\gamma$ is a vector of (unknown) parameters, and $\varepsilon_{2}$ is a normally distributed random term with mean 0 and variance equal to $\sigma_{2}^{2}$.

Our econometric model is thus composed of equations (11), (12) and (13). In this model, the error terms are assumed to be normally distributed:

$$
\left(\begin{array}{l}
\varepsilon_{0} \\
\varepsilon_{1} \\
\varepsilon_{2}
\end{array}\right) \sim \mathcal{N}\left(\left(\begin{array}{l}
0 \\
0 \\
0
\end{array}\right), \Sigma=\left[\begin{array}{ccc}
1 & \sigma_{01} & 0 \\
\sigma_{01} & \sigma_{1}^{2} & \sigma_{12} \\
0 & \sigma_{12} & \sigma_{2}^{2}
\end{array}\right]\right)
$$

\footnotetext{
${ }^{13} \mathrm{~A}$ ten per cent increase in the level of the tax reduction implies that the coefficient 0.5 is replaced by 0.45 in definition (9) and in equation (10).
} 
For practical convenience, correlation between $\varepsilon_{2}$ and $\varepsilon_{0}$ (namely, between random terms affecting preferences and the decision to take advantage of the tax reduction) is constrained to be zero. Under assumption (14), the decision to take advantage of the tax reduction is exogenous if and only if the covariance $\sigma_{01}$ is equal to zero. Otherwise it is endogenous.

Our econometric model is a generalized type 2 Tobit model. ${ }^{14}$ Such a model belongs to the class of models with self-selectivity that are consistently estimated by maximum likelihood procedures. In general, OLS estimates of the price equation parameters $\delta$, based on the subsample of households using domestic help, are inconsistent. In our framework self selectivity comes from the fact that a household with characteristics $\left(Z_{p}, Z_{d}, Z_{b}\right)$ and with income $R$ chooses to consume domestic help according to the condition (7) given in Section 2. Under our assumptions, this condition becomes:

$$
\begin{aligned}
\operatorname{Pr}(a & >0)=\operatorname{Pr}\left[\ln B+(\alpha-1) \ln \lambda+(1-\beta) \ln R \geq \ln p_{a}\right] \\
& =\operatorname{Pr}\left[\varepsilon_{2}-\varepsilon_{1} \geq-Z_{b} \gamma-(\alpha-1) \ln \lambda-(1-\beta) \ln R+Z_{p} \delta+\left(r_{d} \times Z_{p}\right) \eta\right]
\end{aligned}
$$

This last equation shows that the parameters $\alpha$ and $\lambda$ cannot be separately identified from the constant term in $Z_{b} \gamma$ and $Z_{p} \delta$. Thus, for identifiability reasons, $\lambda$ is set equal to 1 . Another identifying assumption, which is usual for this type of Tobit model (see, for instance, Maddala, 1983, p. 229), has to be imposed: at least one regressor included in the covariate vector $Z_{p}$ has to be excluded from the covariate vector $Z_{b}$. In our application, this excluded variable is the dummy variable $k_{6}$. This age-discontinuity exogenous condition follows from the possibility for the household to receive the $A G E D$ allowance for child care in the home if the household comprises at least one child less than six. ${ }^{15}$ As suggested by Table 2 , which is produced with another data source, this age-discontinuity indicator can reasonably be excluded from the covariate vector $Z_{b}$ affecting the household preferences.

This table, that reports the number of households using in-home services given the age of the youngest kid living in the household, would be less reliable with our sample, because of its limited size (let us recall that our sample contains only 174 households using in-home services and only 80 households taking advantage of the tax reduction). For instance, among the 174 households using in-home

\footnotetext{
${ }^{14}$ See, for instance, Amemiya, 1985, p. 385-387.

${ }^{15}$ See point 2 and note 1 in the introduction, and definition (9) in the previous section.
} 
services, only 52 households include at least one kid less than 6 years old, while 40 households have no children. Among the 80 households using in-home services and benefiting from the tax reduction, only 27 households include at least one kid less than 6 years old, while 16 households have no children at all.

Thus, to give some evidence about the discontinuity at age 6 , we use a larger dataset coming from the "Budget des Familles" survey conducted by INSEE (Paris) in 1995, one year before the survey that we use for our study. The "Budget des Familles" survey, which concerns 10,007 households, indicates whether the household pays someone for in-home services or not, and we observe if this person is employed by the household for child-caring exclusively. Unfortunately, we don't observe in this survey whether a household using in-home services receives the AGED allowance or not. ${ }^{16}$ Table 2 gives the number of households employing someone for in-home services, and among these households, the number of those who employ the person exclusively for child-caring, according to the age of the youngest kid living in the household. This table shows that, in this sample, 178 households consume in-home services and include at least one child less than 6 years old. Numbers reported in Table 2 support reasonably well our discontinuity assumption: they show that the number of households paying someone for in-home services (respectively, employing a nanny) is divided by 1.5 (respectively, by 2.2) when the age of the youngest kid goes from 6 to 7 years old.

Due to our specification assumptions, there is no need for differentiating the covariate vector $Z_{b}$ affecting the household preferences from the vector $Z_{d}$ affecting the decision to benefit from the tax reduction. However, to minimize slightly the strength of the assumption of a multivariate normal distribution, we will use an overidentifying restriction by excluding from the vector $Z_{d}$ one covariate which is included in the vector $Z_{b}$. This variable is a proxy for the surface of the household's apartment or house, and which may affect its preferences to consume in-home services (especially, cleaning services); it is a dummy variable that takes the value 1 if the apartment or house has more than four rooms, 0 otherwise. The analytical expression of the likelihood function is given in the Appendix.

\footnotetext{
${ }^{16}$ Moreover, it is very difficult with this survey to calculate the hourly wage paid by the household to the employee. Consequently it would not be possible to estimate our structural model with data coming from the "Budget des Familles" survey.
} 
Table 2

Numbers of households using in-home services, according to the age of the youngest kid living in the household

\begin{tabular}{|c|c|c|c|c|c|c|c|c|c|}
\hline Age of the youngest kid living in the household & 0 & 1 & 2 & 3 & 4 & 5 & 6 & 7 & 8 \\
\hline Number of households consuming in-home services & 37 & 43 & 22 & 17 & 18 & 22 & 19 & 13 & 15 \\
\hline Number of households employing a nanny & 23 & 31 & 7 & 11 & 10 & 12 & 11 & 5 & 8 \\
\hline
\end{tabular}

\section{Results}

We have estimated two models. In the first model, called model A, the decision to benefit from the tax reduction is assumed to be exogenous, which means that, under the normality assumption, the covariance $\sigma_{01}$ between the perturbations affecting prices and the willingness to employ a "regular" worker at home (and to take advantage of the tax reduction) is constrained to be zero. In the second model, called model B, this covariance may be different from zero, which means that it is estimated freely. The parameter estimates of these two models are given in Table 3. A likelihood ratio test allows us to reject at the 7 per cent level the null hypothesis that the decision to benefit from the tax reduction is exogenous. ${ }^{17}$ Consequently, we will comment only parameter estimates of model B and, at the end of this section, all our simulations will be based on the estimates of this model.

Table 3 shows that the household preferences for consumption of domestic services, and consequently the probability of consuming such services, which is equal to $\operatorname{Pr}(a>0)$, are strongly influenced by age and by income. The higher the couple's income, the greater this probability: employing a domestic employee represented a net outlay of 900 francs a month on average in 1996. Couples earning less than 115,000 francs a year in 1996 (26\% of the total) made practically no use of paid domestic service, less than $1 \%$ of them being employers. On the other hand, of the households earning more than 220,000 francs a year in 1996, 20\% were employers. The probability of using domestic help increases with income: almost $40 \%$ of couples earning more than 400,000 francs a year (4\% of the total) paid a cleaning lady.

\footnotetext{
${ }^{17}$ The likelihood ratio test statistic is equal to 3.3907 , which corresponds to a $p$-value equal to 0.06556 .
} 
Couples headed by an executive constitute $54 \%$ of employing households, although accounting for only $18 \%$ of couples. At the other extreme, only one couple in a hundred where the head is a blue-collar worker consumes this type of service. It is also couples where the wife is an executive or practices a profession that most employ a cleaning lady, one in three being employers. Couples who are executives are three times as likely to have a domestic employee as couples in general (the proportions being $18 \%$ and $6 \%$, respectively). Our estimates are in line with these descriptive statistics: other things being equal, the household preferences for consumption of domestic services, and consequently the probability to hire a domestic employee, are much higher when the woman is an executive (see Table 3). ${ }^{18}$ Executives generally receive relatively high market wages; in other terms, their working time has a high price. Someone who attributes a higher price to his or her own time than the hourly cost of a domestic employee has an interest in delegating household tasks. On the other hand, someone whose hourly wage is below the hourly cost of the domestic employee has an interest in carrying out household tasks, even at the cost of working less. ${ }^{19}$ In terms of opportunity costs, the individuals using such domestic help are those with a high productivity on the labor market, at least equal to that prevailing in the sector of domestic services. ${ }^{20}$

Sociological studies have reached the conclusion that in low social classes, social norms induce the woman to play her role of housewife and to do all the domestic work herself (see, among many others, Goffman, 1977, Berk, 1985, and Brines, 1994). Other explanations could be invoked to explain why executives and people with higher qualifications resort more often to a cleaning lady's services. Apart from the fact that they are more accustomed to delegate work, their trade-off between consumption and leisure is more often in favour of domestic services because their working time (journeys included) is longer (see Fermanian and Baessa, 1997) and because they try to free more time for leisure (excluding domestic activity).

Neither the number of children nor women's work seems to influence the household preferences for consumption of domestic services (see Table 3). When the domestic work represents a heavy burden or when the time that can be devoted to it is scarce, the consumption of domestic services could be expected to become more prevalent. Logically, lack of available time for domestic activities ought to

\footnotetext{
${ }^{18}$ However, a high educational level is not found to affect the household preferences.

${ }^{19}$ This is an application of Becker's classical argument on the allocation of time (see Becker, 1965, 1991).

${ }^{20}$ For a more general theoretical analysis of this point, see Blanchet (1994).
} 
incite couples both of whose members work to delegate their domestic tasks more often. Couples in which the wife has a job do indeed employ a cleaning lady 2.5 times as often as those in which the wife is not employed: $6.6 \%$ compared with 2.7\% (see Flipo and Hourriez, 1996). However, the fact that labor market participation of both members of the couple is more often accompanied by employing a cleaning lady is mainly because the wife's work brings in additional income and because a qualified woman has a greater chance of being in work than one with few qualifications. At a given standard of living and social level, the labor market participation of the woman - and the resulting reduction in free time - raises only slightly the probability of hiring a domestic employee. In fact, what leads to use domestic services is above all the fact that the woman is - or has been in the past - an executive and much less the fact that she is actually working. One woman executive in three employs a domestic employee whether she works or not, whereas a white-collar woman virtually never does, even when she is working. Ceteris paribus, the apparent effect of female working fades into insignificance compared with the much stronger effects of income and professional qualification. Finally, the overidentifying dummy variable "having a house or an apartment with more than four rooms" has no significant effect on the household preferences and, consequently, on the probability to consume domestic services.

The probability to take advantage of the tax reduction (that we interpret as the probability to hire a "regular" domestic employee) is higher when the woman is a mid-level worker or an executive (but it decreases when the man is an executive). It is lower when the woman is working but has less than one child, and when the household lives in Paris (see Table 3). This last result may be explained by the scarcity of high-quality domestic workers in Paris, and by the fact these workers, having then a higher bargaining power, may obtain that the households do not declare them to the tax administration and thus pay them a higher (net) wage. This argument is in line with the fact that hourly net wages are estimated to be higher in Paris (see Table 3). The probability that the household takes advantage of the tax reduction increases with the household income. In fact, households facing a relatively high market price (before tax reduction) have a strong incentive to benefit from the tax reduction, and descriptive statistics show that such households are more frequently high-income households. ${ }^{21}$ As expected,

\footnotetext{
${ }^{21}$ In the subsample of households consuming in-home services, the average hourly net price $\widetilde{p}_{a}$ (before tax reduction) paid by households whose income is higher than the third quartile of the sample income distribution is equal to 47.77 French Francs (FF). For households whose income is lower than the first quartile, it is equal to $36.66 \mathrm{FF}$. Finally, for households whose income
} 
the correlation coefficient $\sigma_{01}$ between the random term $\varepsilon_{0}$ affecting the probability of taking advantage of the tax reduction and the perturbation $\varepsilon_{1}$ affecting the net hourly price which is effectively paid by the household, is estimated to be negative (at the 7 per cent significance level).

Neither the socio-professional category of the employing household, nor its level of education provides an explanation for the price of domestic services observed in the survey (see Table 3, continued). ${ }^{22}$ As we have already noticed, households living in Paris face higher prices before tax reduction (see Table 3, continued). However, this variable is found to have no statistically significant effect on the net hourly price after tax reduction. The presence of at least one kid less than six years old corresponds to a lower price, after but also before tax reduction (see Table 3, continued). The first effect (decreasing the price after tax reduction) is directly implied by the tax credit schedule (see equation (9)), the second effect (decreasing the price before tax reduction) is less expected. It may be explained by the fact that individuals (especially, young women) offering baby-sitting services to households are probably more numerous than those who supply other activities, such as housework or care for an elderly or handicapped person. Finally, let us remark that the correlation coefficient $\sigma_{12}$ between the random term $\varepsilon_{1}$ affecting the net hourly price which is effectively paid by the household and the perturbation $\varepsilon_{2}$ affecting the household preferences is estimated to be positive (at a very high statistical significance level). This means that, other observable things being equal, households having a strong preference for consuming in-home services have also a higher willingness-to-pay.

value is between the first and second (respectively, the second and third) quartiles, it is equal to $37.24 \mathrm{FF}$ (respectively, to $44.00 \mathrm{FF}$ ).

${ }^{22}$ These variables, whose effects on the hourly net price before tax reduction are not statistically significant, have not been introduced into the vector of covariates interacting with the tax reduction indicator $r_{d}$. Only those having a statistically significant effect on this price (namely, "living or not in Paris", and "having or not a child less than 6 years old") have been incorporated into the vector $r_{d} \times Z_{p}$ (see equation (11)). 
Table 3

Maximum likelihood estimates of the model parameters

\begin{tabular}{|c|c|c|c|c|}
\hline & \multicolumn{4}{|c|}{ The decision to benefit from the tax reduction is } \\
\hline & \multicolumn{2}{|c|}{ exogenous (model A) } & \multicolumn{2}{|c|}{ endogenous (model B) } \\
\hline \multicolumn{5}{|c|}{ Decision to benefit from the tax reduction } \\
\hline Intercept & -5.814 & $(2.164)$ & -6.634 & $(2.539)$ \\
\hline Living in Paris & -0.964 & $(3.604)$ & -0.879 & $(3.310)$ \\
\hline Log (income) & 0.528 & $(1.923)$ & 0.626 & $(2.454)$ \\
\hline \multicolumn{5}{|l|}{ The woman is working } \\
\hline and has less than one kid & -0.571 & $(2.513)$ & -0.471 & $(1.990)$ \\
\hline The woman is highly educated & -0.367 & $(1.275)$ & -0.332 & $(1.140)$ \\
\hline The woman is a mid-level worker & 0.969 & $(2.867)$ & 1.064 & $(3.281)$ \\
\hline The woman is an executive & 1.732 & $(4.495)$ & 1.750 & $(4.584)$ \\
\hline The woman is self-employed & 0.936 & $(1.885)$ & 0.875 & $(1.714)$ \\
\hline The man is highly educated & 0.464 & $(1.695)$ & 0.440 & $(1.626)$ \\
\hline The man is an executive & -0.463 & $(1.665)$ & -0.507 & $(1.835)$ \\
\hline \multicolumn{5}{|c|}{ Preferences } \\
\hline Intercept & 1.230 & $(2.592)$ & 1.156 & $(2.473)$ \\
\hline Living in Paris & 0.136 & $(2.127)$ & 0.121 & $(1.859)$ \\
\hline Log (income) & 0.212 & $(4.417)$ & 0.220 & $(4.653)$ \\
\hline \multicolumn{5}{|l|}{ The woman is working } \\
\hline and has less than one kid & 0.037 & $(0.973)$ & 0.019 & $(0.521)$ \\
\hline and has at least two kids & 0.049 & $(1.236)$ & 0.044 & $(1.155)$ \\
\hline The woman is highly educated & 0.028 & $(0.399)$ & 0.014 & $(0.200)$ \\
\hline The woman is a mid-level worker & 0.113 & $(1.393)$ & 0.125 & $(1.534)$ \\
\hline The woman is an executive & 0.159 & $(1.708)$ & 0.192 & $(2.011)$ \\
\hline The woman is self-employed & 0.169 & $(1.440)$ & 0.177 & $(1.506)$ \\
\hline The man is highly educated & 0.019 & $(0.277)$ & 0.030 & $(0.443)$ \\
\hline The man is a mid-level worker & 0.007 & $(0.040)$ & 0.008 & $(0.082)$ \\
\hline The man is an executive & 0.121 & $(0.946)$ & 0.113 & $(1.158)$ \\
\hline The man is self-employed & 0.051 & $(0.395)$ & 0.062 & $(0.602)$ \\
\hline The man is between 35 and 45 & 0.053 & $(1.122)$ & 0.051 & $(1.131)$ \\
\hline The man is between 45 and 55 & 0.108 & $(2.051)$ & 0.101 & $(2.007)$ \\
\hline The man is between 55 and 65 & 0.150 & $(2.594)$ & 0.142 & $(2.551)$ \\
\hline More than four rooms & 0.032 & $(1.034)$ & 0.034 & $(1.159)$ \\
\hline
\end{tabular}


Table 3 (continued)

Maximum likelihood estimates of the model parameters

\begin{tabular}{|c|c|c|c|c|}
\hline & \multicolumn{4}{|c|}{ The decision to benefit from the tax reduction is } \\
\hline & \multicolumn{2}{|c|}{ exogenous (model A) } & \multicolumn{2}{|c|}{ endogenous (model B) } \\
\hline \multicolumn{5}{|c|}{ Hourly net wage } \\
\hline Intercept & 4.031 & $(23.577)$ & 3.951 & $(25.520)$ \\
\hline Living in Paris & 0.115 & $(1.798)$ & 0.134 & $(2.097)$ \\
\hline At least one kid less than 6 & -0.093 & $(2.379)$ & -0.089 & $(2.395)$ \\
\hline The woman is highly educated & -0.041 & $(0.619)$ & -0.038 & $(0.571)$ \\
\hline The woman is a mid-level worker & 0.091 & $(1.165)$ & 0.065 & $(0.822)$ \\
\hline The woman is an executive & 0.105 & $(1.203)$ & 0.080 & $(0.895)$ \\
\hline The woman is self-employed & 0.136 & $(1.201)$ & 0.114 & $(1.001)$ \\
\hline The man is highly educated & -0.039 & $(0.616)$ & -0.043 & $(0.673)$ \\
\hline The man is a mid-level worker & 0.001 & $(0.007)$ & 0.002 & $(0.025)$ \\
\hline The man is an executive & 0.055 & $(0.440)$ & 0.068 & $(0.726)$ \\
\hline The man is self-employed & -0.035 & $(0.276)$ & -0.019 & $(0.195)$ \\
\hline Tax reduction & -0.539 & $(6.171)$ & -0.523 & $(6.087)$ \\
\hline Tax reduction and living in Paris & -0.031 & $(0.330)$ & -0.056 & $(0.601)$ \\
\hline Tax reduction and one kid less than 6 & -0.227 & $(2.844)$ & -0.207 & $(2.638)$ \\
\hline \multicolumn{5}{|c|}{ Covariance matrix } \\
\hline Standard error of prices $\left(\sigma_{1}\right)$ & 0.335 & $(14.650)$ & 0.333 & $(15.283)$ \\
\hline Standard error of preferences $\left(\sigma_{2}\right)$ & 0.328 & $(13.213)$ & 0.330 & $(13.484)$ \\
\hline Covariance reduction-prices $\left(\sigma_{01}\right)$ & 0 & & -0.164 & $(1.816)$ \\
\hline Covariance preferences-prices $\left(\sigma_{12}\right)$ & 0.073 & $(5.349)$ & 0.092 & $(7.650)$ \\
\hline Mean log-likelihood & \multicolumn{2}{|c|}{-0.140461} & \multicolumn{2}{|c|}{-0.139879} \\
\hline Sample size & \multicolumn{4}{|c|}{2913} \\
\hline
\end{tabular}

Sample: Couples whose head has between 25 and 64 years old $(N=2913)$.

Source: "Services de proximité" Survey, INSEE (1996).

Remark: $t$ statistics in parentheses. 
We have conducted different simulations on the basis of these parameter estimates. All these simulations are obtained by applying the Geweke-HajivassiliouKeane (GHK) recursive simulator. ${ }^{23}$ This procedure allows us to draw, for example, one hundred replications of the vector $\left(\varepsilon_{0}, \varepsilon_{1}, \varepsilon_{2}\right)$ for each household. For a household that is observed to consume in-home services, each vector is drawn by taking into account the fact that $\varepsilon_{2}-\varepsilon_{1}$ has to be greater than the estimated value of the quantity $Z_{p} \delta-Z_{b} \gamma-(1-\beta) \ln R$, and also that the household is observed either to take advantage of the tax reduction (in that case, $\varepsilon_{0}$ has to be greater than the estimated value of the expression $-Z_{d} \mu+Z_{p} \eta$ ) or not (in this second case, $\varepsilon_{0}$ has to be lower than the estimated value of the expression $\left.-Z_{d} \mu+Z_{p} \eta\right){ }^{24}$ For a household that is observed not to consume in-home services, each vector is drawn by taking only into account the fact that $\varepsilon_{2}-\varepsilon_{1}$ has to be lower than the estimated value of the quantity $Z_{p} \delta-Z_{b} \gamma-(1-\beta) \ln R$.

In a first exercise, we have simulated the net hourly prices $\widetilde{p}_{a}$ that should have been paid by households who do not actually consume in-home services, would they have consumed. ${ }^{25}$ Results of this exercise are given in Table 4, whose structure is chosen to be similar to the structure of Table 1 for facilitating comparisons. These results show that the overall mean and median of these simulated prices are approximately 11 French Francs higher than the overall mean and median of prices that are observed to be paid by households actually using domestic services. This result is also verified inside different strata (households having or not having at least one kid less than six years old, households living or not living in Paris, households taking or not taking advantage of the tax reduction). Moreover, the prices $\widetilde{p}_{a}$ that should have been paid by households that do not employ domestic workers are more dispersed than prices paid by households actually consuming domestic services (the interdecile ratios of their marginal and conditional distributions are

\footnotetext{
${ }^{23}$ See, for instance, Greene (2000, p. 184-185) for a brief description of this algorithm, or the seminal papers by Geweke (1991), Hajivassiliou (1991), and Keane (1994).

${ }^{24} \mathrm{An}$ evaluation of the fit of the model can be obtained with the GHK procedure by taking only into account the fact that $\varepsilon_{2}-\varepsilon_{1}$ has to be greater than the estimated value of the quantity $Z_{p} \delta-Z_{b} \gamma-(1-\beta) \ln R$ for each household, and by generating recursively $\varepsilon_{0}$ given the value of the residual $\varepsilon_{2}-\varepsilon_{1}$ that has been drawn just before, but without considering the observed decision to take (or not) advantage of the tax reduction. For 45.97 percent of the 1,000 simulations that were drawn for households consuming in-home services, the corresponding decision is not to take advantage of the tax reduction. In the subsample of households consuming in-home services, the percentage of households that do actually benefit from the tax reduction is observed to be equal to 45.89 (see Table 1). Thus, based on this criterion, the fit of the model is quite good.

${ }^{25}$ By definition, for households who do not consume in-home services, this price is higher than their reservation price.
} 
higher; see Table 4). Finally, the estimated proportion of households that do not consume in-home services but would like to benefit from the tax reduction would they consume is equal to 19.38 per cent (see Table 4).

Table 4

The simulated hourly net wage, in francs, that should have been paid by households who do not actually use domestic services, would they have consumed

\begin{tabular}{llllllll}
\hline $\begin{array}{l}\text { Hourly net wage } \\
\left(\widetilde{p}_{a}\right)\end{array}$ & Overall & $\begin{array}{l}\text { At least one kid } \\
\text { less than } 6\end{array}$ & $\begin{array}{l}\text { No kids } \\
\text { less than } 6\end{array}$ & $\begin{array}{l}\text { Living in } \\
\text { Paris }\end{array}$ & $\begin{array}{l}\text { Not living } \\
\text { in Paris }\end{array}$ & $\begin{array}{l}\text { With tax } \\
\text { reduction }\end{array}$ & $\begin{array}{l}\text { Without tax } \\
\text { reduction }\end{array}$ \\
\hline Mean & 57.04 & 48.85 & 54.14 & 61.03 & 50.92 & 50.72 & 58.56 \\
Median & 53.82 & 47.18 & 51.52 & 58.29 & 48.58 & 48.14 & 55.31 \\
1st quartile & 42.94 & 34.45 & 37.98 & 44.73 & 35.59 & 38.59 & 44.20 \\
3rd quartile & 67.60 & 60.74 & 66.91 & 73.90 & 63.19 & 59.91 & 69.28 \\
Interdecile ratio & 2.37 & 3.29 & 3.01 & 2.73 & 3.08 & 2.31 & 2.35 \\
\hline \multicolumn{7}{l}{$\begin{array}{l}\text { Proportion } \\
\text { Subsample: Couples whose head has between 25 and } 64 \text { years old and who do not use domestic help }\left(N_{0}=2739\right) .\end{array}$} \\
Source: Estimates obtained by the authors using the survey "Services de proximité", INSEE $(1996)$.
\end{tabular}

A second exercise consists in evaluating the effects of a ten per cent increase in the tax reduction. This "reform" implies to substitute 0.45 to 0.5 in the schedule defined in (9), or in other terms, to add $\ln (0.9)$ to the intercept of the estimate of the difference $Z_{p} \eta$ between the price before and after reduction.appearing in equations (11) and (12).Results of this simulation exercise are the following:

1. a ten per cent increase in the tax reduction would increase by 4.89 points the proportion of households asking to benefit from the tax reduction among the households who were already consuming in-home services before the increase in the tax reduction; this proportion goes then from 45.89 per cent (which is the observed proportion of households benefiting from the tax reduction among those consuming in-home services; see Table 1) to 50.78 per cent (which is the proportion predicted by simulation); this increase corresponds to a "regularization" of domestic workers who were previously irregularly employed (namely, employed without being declared to the tax administration); this "regularization" comes mainly from high-income households (for instance, households whose income is higher than the third quartile of the income sample distribution represent 79.72 per cent of the increase of 4.89 points in percentage), and from households without a kid less than 6 years old (such households represent 71.28 per cent of these 4.89 points); on the 
whole, those households contributing mainly to this "regularization" of domestic employees are the high-income households without a kid less than six (such households represent 57.63 per cent of the households who were not benefiting from the tax reduction before the "reform", but who are now taking advantage of it);

2. among households who did not consume in-home services, 13.51 per cent consume such services after the ten per cent increase in the tax reduction, which is a quite significant proportion; among these 13.51 per cent of households, 42.19 per cent have an income higher than the third quartile of the income sample distribution, 87.94 per cent do not live in Paris, and 73.14 have no kid less than six years old.

\section{Conclusions}

In this paper we have studied the impact of tax reductions on the demand for services in the home. For that purpose, we have estimated a structural model of demand for such services by using household individual data collected by INSEE (Paris) in 1996. In this model, the net hourly wage paid to the domestic employee, the household preferences for consumption of in-home services and the decision to take advantage of the tax reduction are considered as endogenous variables. Estimation of the econometric model uses the fact that some households are observed to consume domestic services and to take advantage of the tax reduction, while others either consume such services but do not take advantage of the tax reduction, or do not consume these services at all. Identification of the econometric model relies on an exclusion restriction resulting from the tax credit schedule; namely, the presence of a kid less than six years old in the household affects (by law) the net hourly price actually paid, but this age-discontinuity dummy variable is assumed not to influence directly the household preference for consumption of in-home services and the household decision to take advantage of the tax reduction.

Results show that the probability of consuming in-home services increases with age and income. Other things being equal, this probability is much higher when the woman is an executive, but neither the number of children nor women's work seems to influence it. The probability to take advantage of the tax reduction (that we interpret as the probability to hire a "regular" domestic employee) is higher when the woman is a mid-level worker or an executive (but it decreases 
when the man is an executive). Our simulations show that a ten per cent increase in the tax reduction would increase from 45.9 to 50.8 per cent the proportion of households benefiting from the tax reduction among those who consume paid inhome services. Moreover, 13.5 per cent of households who do not actually consume such services would do so after the ten per cent increase in the tax reduction. ${ }^{26}$ These changes in proportions would mainly concern high-income households.

However, our model and our data do not allow us to answer the question about the number of service jobs created at the aggregate level by the law on tax reduction. A model formalizing both sides of the market (and the corresponding statistical information) would be necessary for that purpose. Nevertheless, the incorporation of the household decision to benefit from the tax reduction allows us to examine what would be the effects of an increase of the tax reduction on the employment of "irregular" workers (who are not declared to the tax administration by households). Our simulation exercise has shown that increasing the tax reduction would be substantially beneficial to "regular" employment in the sector of services in the home.

\section{Acknowledgements}

We thank David Blau, Gilbert Cette, Jean-Michel Hourriez, Guy Laroque, Stefan Lollivier, as well as participants at the 54th European Meeting of the Econometric Society (Santiago de Compostela, 29 August -1 September 1999) and in seminars at INSEE (Paris) and Conseil d'Analyse Economique (Paris), for helpful comments on a previous draft. Remarks and suggestions made by two anonymous referees and the co-editor, Thomas Piketty, helped us to improve significantly the first version of this paper. The usual disclaimers apply.

\section{Appendix. The likelihood function}

To deduce the likelihood function of our econometric model, first let us recall some well-known results about conditional multivariate distributions (see, for instance, Greene, 2000, p.87). If the vector $\left(\varepsilon_{0}, \varepsilon_{1}, \varepsilon_{2}\right)^{\prime}$ is generated by the normal

\footnotetext{
${ }^{26}$ To be precise, let us recall that here we consider only couples whose head has between 25 and 64 years old, single people and couples at least one of whom needs permanent care being excluded from our study.
} 
distribution $\mathcal{N}(0, \Sigma)$ (see equation 14$)$, then the vector $\left(\varepsilon_{0}, \varepsilon_{2}\right)^{\prime}$ has a conditional normal distribution given $\varepsilon_{1}$, which is:

$$
\left(\begin{array}{l}
\varepsilon_{0} \\
\varepsilon_{2}
\end{array}\right) \mid \varepsilon_{1} \sim \mathcal{N}\left(\left(\begin{array}{c}
\sigma_{01} \varepsilon_{1} / \sigma_{1}^{2} \\
\sigma_{12} \varepsilon_{1} / \sigma_{1}^{2}
\end{array}\right), \Sigma_{02.1}\right)
$$

with covariance matrix

$$
\Sigma_{02.1}=\left[\begin{array}{cc}
1-\rho_{1}^{2} & -\rho_{1} \rho_{2} \sigma_{2} \\
-\rho_{1} \rho_{2} \sigma_{2} & \sigma_{2}^{2}\left(1-\rho_{2}^{2}\right)
\end{array}\right]
$$

and with corresponding correlation matrix

$$
\Gamma_{02.1}=\left[\begin{array}{cc}
1 & \frac{-\rho_{1} \rho_{2}}{\sqrt{\left(1-\rho_{1}^{2}\right)\left(1-\rho_{2}^{2}\right)}} \\
\frac{-\rho_{1} \rho_{2}}{\sqrt{\left(1-\rho_{1}^{2}\right)\left(1-\rho_{2}^{2}\right)}} & 1
\end{array}\right]
$$

In these two last expressions, $\rho_{1}$ and $\rho_{2}$ are defined as:

$$
\rho_{1}=\sigma_{01} / \sigma_{1} \text { and } \rho_{2}=\sigma_{12} /\left(\sigma_{1} \sigma_{2}\right)
$$

Consequently

$$
\left(\begin{array}{c}
{\left[\varepsilon_{0}-\sigma_{01} \varepsilon_{1} / \sigma_{1}^{2}\right] / \sqrt{1-\rho_{1}^{2}}} \\
{\left[\varepsilon_{2}-\sigma_{12} \varepsilon_{1} / \sigma_{1}^{2}\right] /\left[\sigma_{2} \sqrt{1-\rho_{2}^{2}}\right]}
\end{array}\right) \mid \varepsilon_{1} \sim \mathcal{N}\left(0, \Gamma_{02.1}\right)
$$

Let us denote $f_{1}($.$) the marginal density function of \varepsilon_{1}$ and $\Phi_{2, \Gamma_{02.1}}(.,$.$) the c.d.f.$ of the bivariate normal distribution $\mathcal{N}\left(0, \Gamma_{02.1}\right) .{ }^{27}$ Then the contribution to the likelihood function of a household that consumes domestic services $(a>0)$ at price $p_{a}$ by taking advantage of the tax reduction $\left(r_{d}=1\right)$ is equal to:

$$
\begin{gathered}
f_{1}\left(\varepsilon_{1}\right) \times \operatorname{Pr}\left(\varepsilon_{0}>-Z_{d} \mu+Z_{p} \eta, \varepsilon_{2}>\ln p_{a}-Z_{b} \gamma-(1-\beta) \ln R \mid \varepsilon_{1}\right) \\
=\frac{1}{\sigma_{1}} \varphi\left(\frac{\varepsilon_{1}}{\sigma_{1}}\right) \times\left[1-\Phi\left(W_{0}\right)-\Phi\left(W_{1}\right)+\Phi_{2, \Gamma_{02.1}}\left(W_{0}, W_{1}\right)\right]
\end{gathered}
$$

\footnotetext{
${ }^{27}$ This c.d.f. is calculated by the function $c d f b v n$ included in the software Gauss 5.0 that has been used for estimating the maximum likelihood estimates of the model parameters.
} 
with

$$
\begin{aligned}
& W_{0}=\frac{-Z_{d} \mu+Z_{p} \eta-\sigma_{01} \varepsilon_{1} / \sigma_{1}^{2}}{\sqrt{1-\rho_{1}^{2}}}, \\
& W_{1}=\frac{\ln p_{a}-Z_{b} \gamma-(1-\beta) \ln R-\sigma_{12} \varepsilon_{1} / \sigma_{1}^{2}}{\sigma_{2} \sqrt{1-\rho_{2}^{2}}}, \\
& \varepsilon_{1}=\ln p_{a}-\left[Z_{p} \delta+\left(r_{d} \times Z_{p}\right) \eta\right],
\end{aligned}
$$

$\Phi$ and $\varphi$ being respectively the c.d.f. and the density function of the standard normal distribution. Analogously, the contribution to the likelihood function of a household that consumes domestic services $(a>0)$ at price $p_{a}$ by not taking advantage of the tax reduction $\left(r_{d}=0\right)$ is equal to:

$$
\begin{aligned}
& f_{1}\left(\varepsilon_{1}\right) \times \operatorname{Pr}\left(\varepsilon_{0}<-Z_{d} \mu+Z_{p} \eta, \varepsilon_{2}>\ln p_{a}-Z_{b} \gamma-(1-\beta) \ln R \mid \varepsilon_{1}\right) \\
& \quad=\frac{1}{\sigma_{1}} \varphi\left(\frac{\varepsilon_{1}}{\sigma_{1}}\right) \times\left[\Phi\left(W_{0}\right)-\Phi_{2, \Gamma_{02.1}}\left(W_{0}, W_{1}\right)\right]
\end{aligned}
$$

where $W_{0}$ and $W_{1}$ are defined as above, but $\varepsilon_{1}$ is now equal to $\ln p_{a}-Z_{p} \delta$. Finally, the contribution to the likelihood function of a household that does not consume domestic services $(a=0)$ is equal to:

$$
\operatorname{Pr}(a=0)=\operatorname{Pr}\left(a=0, r_{d}=0\right)+\operatorname{Pr}\left(a=0, r_{d}=1\right)
$$

When calculating this contribution for a household in which $a=0$, we have to consider what it would do in the event that it did consume (take advantage of the tax reduction or not). Under our assumptions,

$\operatorname{Pr}\left(a=0, r_{d}=0\right)=\operatorname{Pr}\left(\varepsilon_{0}<-Z_{d} \mu+Z_{p} \eta \frac{\varepsilon_{2}-\varepsilon_{1}}{\sigma}<\frac{Z_{p} \delta-Z_{b} \gamma-(1-\beta) \ln R}{\sigma}\right)$

where $\sigma=\sqrt{\sigma_{1}^{2}+\sigma_{2}^{2}-2 \sigma_{12}}$. But let us remark that the vector $\left(\varepsilon_{0}, \frac{\varepsilon_{2}-\varepsilon_{1}}{\sigma}\right)^{\prime}$ has a bivariate standard normal distribution with correlation equal to $\varpi=-\sigma_{01} / \sigma$, namely:

$$
\left(\begin{array}{c}
\varepsilon_{0} \\
\frac{\varepsilon_{2}-\varepsilon_{1}}{\sigma}
\end{array}\right) \sim \mathcal{N}\left(\left(\begin{array}{l}
0 \\
0
\end{array}\right),\left[\begin{array}{cc}
1 & \varpi \\
\varpi & 1
\end{array}\right]\right)
$$


If we denote $\Phi_{2, \varpi}(.,$.$) the c.d.f. of this bivariate normal distribution, then$

$$
\operatorname{Pr}\left(a=0, r_{d}=0\right)=\Phi_{2, \varpi}\left(-Z_{d} \mu+Z_{p} \eta, \frac{Z_{p} \delta-Z_{b} \gamma-(1-\beta) \ln R}{\sigma}\right)
$$

and

$$
\begin{aligned}
\operatorname{Pr}\left(a=0, r_{d}=1\right)= & \Phi\left(\frac{Z_{p}(\delta+\eta)-Z_{b} \gamma-(1-\beta) \ln R}{\sigma}\right) \\
& -\Phi_{2, \varpi}\left(-Z_{d} \mu+Z_{p} \eta, \frac{Z_{p}(\delta+\eta)-Z_{b} \gamma-(1-\beta) \ln R}{\sigma}\right)
\end{aligned}
$$

Thus the contribution to the likelihood function of a household that does not consume domestic services $(a=0)$ is equal to:

$$
\begin{gathered}
\Phi\left(\frac{Z_{p}(\delta+\eta)-Z_{b} \gamma-(1-\beta) \ln R}{\sigma}\right) \\
+\Phi_{2, \varpi}\left(-Z_{d} \mu+Z_{p} \eta, \frac{Z_{p} \delta-Z_{b} \gamma-(1-\beta) \ln R}{\sigma}\right) \\
\quad-\Phi_{2, \varpi}\left(-Z_{d} \mu+Z_{p} \eta, \frac{Z_{p}(\delta+\eta)-Z_{b} \gamma-(1-\beta) \ln R}{\sigma}\right)
\end{gathered}
$$

\section{References}

Amemiya, T., 1985. Advanced Econometrics, Basil Blackwell, Oxford.

Antonnen, A., Spiliä, J., 1996. European Social Care Services: Is it Possible to Identify Models?. Journal of European Social Policy 6(2), 87-100.

Averett, S., Peters, E., Waldman, D., 1997. Tax Credits, Labor Supply, and Child Care. The Review of Economics and Statistics 79(1), 125-135.

Becker, G., 1965. A Theory of the Allocation of Time. The Economic Journal 75, 493-517.

Becker, G., 1991. A Treatise on the Family, Harvard University Press, Cambridge. 
Berk, S., 1985. The Gender Factory: The Apportionment of Work in American Households, Plenum, New York.

Blanchet, D., 1994. Transferts fiscaux, répartition du revenu et équilibre des emplois de service. Economie et Prévision no. 115, 85-92.

Blau, D., Hagy, A., 1998. The Demand for Quality in Child Care. Journal of Political Economy 106(1), 104-146.

Brines, J., 1994. Economic Dependency, Gender, and the Division of Labor at Home. American Journal of Sociology 100(3), 652-688.

Cealis, R., Zilberman, S., 1997. Les emplois familiaux et les organismes de services aux personnes en 1996. Dares Premières Synthèses no. 461, Paris.

European Commission, 1994. Sources of New Jobs. New Needs, Role of Markets, Public Intervention and Labour Market Policies: An Assessment of the Potential. Forward Studies Unit, mimeo, LP/cab-CdP (94) 255.

Fermanian, J.-D., Baessa, M.P., 1997. La durée du travail à temps complet. Insee Première no. 545, Paris.

Flipo, A., 1996. Les services de proximité de la vie quotidienne. Insee Première no. 491, Paris.

Flipo, A., Hourriez, J.M, 1995. Recourir à une femme de ménage. Insee Première no. 411, Paris.

Gertler, P., Waldman, D., 1992. Quality-adjusted Cost Functions and Policy Evaluation in the Nursing Home Industry. Journal of Political Economy 100(6), 1232-1256.

Geweke, J., 1991. Efficient Simulation from the Multivariate Normal and Studentt Distributions Subject to Linear Constraints. Computer Science and Statistics, Proceedings of the Twenty-Third Symposium on the Interface (Interface Foundation of North-America, Inc., Fairfax), 571-578.

Goffman, E., 1977. The Arrangement between the Sexes. Theory and Society 4, 301-331.

Greene, W. H., 2000. Econometric Analysis, 4th edition, Prentice-Hall International, Upper Saddle River. 
Hajivassiliou V., 1991. Simulation Estimation Methods for Limited Dependent Variable Models. Cowles Foundation Discussion Paper 1007, Yale University.

Keane, M., 1994. A Computationaly Practical Simulation Estimator for Panel Data. Econometrica 62(1), 95-116.

Kimmel, J., 1998. Child Care Costs as a Barrier to Employment for Single and Married Mothers. The Review of Economics and Statistics 80(2), 287-299.

Maddala, G. S., 1983. Limited Dependent and Qualitative Variables in Econometrics, Cambridge University Press, Cambridge.

Nyman, J., Bricker, D., 1989. Profit Incentives and Technical Efficiency in the Production of Nursing Home Care. The Review of Economics and Statistics 71(4), 586-594.

Piketty, T., 1998. L'emploi dans les services en France et aux Etats-Unis: une analyse structurelle sur longue période. Economie et Statistique, no. 318, 73-102.

Preston, I., Labeaga, J. M., Sanchis J. A., 1997. Children and Demand Patterns: Evidence from Spanish Panel Data. Universitat de Valencia, mimeo. 